\title{
Các yếu tố tác động đến kinh doanh du lịch sinh thái trải nghiệm của hộ gia đình và cá nhân trên địa bàn tỉnh Cà Mau nhằm ứng phó với biến đổi khí hậu
}

\section{Factors affecting the ecotourism experience business of households and individuals in Ca Mau province to respond to climate change}

\author{
Nguyễn Phước Hoàng ${ }^{1 *}$
}

${ }^{1}$ Sở Xây dựng tỉnh Cà Mau, Việt Nam

"Tác giả liên hệ, Email: hoangsxd26@gmail.com

\section{THÔNG TIN}

DOI: 10.46223/HCMCOUJS. econ.vi.13.1.533.2018

Ngày nhận: 24/10/2017

Ngày nhận lại: 05/11/2017

Duyệt đăng: 20/12/2017

Tù khóa:

biến đổi khí hậu, kinh doanh du lịch, sinh thái trải nghiệm, tỉnh Cà Mau

\section{TÓM TÁ́T}

Nghiên cứu này được thực hiện với mục tiêu phân tích các yếu tố tác động đến kinh doanh du lịch sinh thái trải nghiệm của hộ gia đình và cá nhân trên địa bàn tỉnh Cà Mau nhằm ứng phó với biến đổi khí hậu. Nghiên cứu sử dụng các phương pháp phân tích số liệu sau: Thống kê, so sánh và phân tích: Thông qua những số liệu sơ cấp và thứ cấp (khảo sát bảng câu hỏi với 130 mẫu để làm căn cứ phân tích, đánh giá công tác kinh doanh du lịch sinh thái trải nghiệm của hộ gia đình và cá nhân trên địa bàn tỉnh Cà Mau. Trong đó tác giả có sử dụng phần mềm SPSS và EXCEL làm công cụ hỗ trợ cho việc phân tích. Kết quả nghiên cứu cho thấy, có 5 nhân tố tác động đến sự tham gia của hộ gia đình, cá nhân vào hoạt động du lịch sinh thái trải nghiệm bao gồm: (i) phúc lợi địa phương, (ii) nguồn tài nguyên du lịch và vốn xã hội, (iii) sự quan tâm của chính quyền, (iv) Văn hóa xã hội địa phương, (v) Cơ sở vật chất - Hạ tầng kỹ thuật - vốn xã hội. Dựa trên kết quả nghiên cứu, tác giả đề xuất một số kiến nghị nhằm nâng cao sự tham gia của hộ gia đình, cá nhân vào hoạt động du lịch sinh thái trải nghiệm.

\section{ABSTRACT}

This research aims to analyze factors affecting to ecotourism business of households and individuals in $\mathrm{Ca}$ Mau province to respond to climate change. The research uses statistics, comparison and analysis methods to analyze and evaluate primary and secondary data collected from a survey of 130 samples of households and individuals doing ecotourism business in Ca Mau province. The author uses SPSS and Excel 
Keywords:

Ca Mau province, climate change, eco-tourism activities, tourism business

as tools for data analysis. The study results showed five factors affecting the participation of households including (1) Local Welfare, (2) Tourism resources and social capital, (3) Concern of authorities, (iv) Local social culture (v) Infrastructure - Technical infrastructure - social capital. Some recommendations were also proposed to enhance the ac ti ve participation of families in ecotourism activities.

\section{1. Đặt vấn đề}

Khủng hoảng môi trường và biến đổi khí hậu đang tác động ngày càng nghiêm trọng đến đời sống kinh tế - xã hội và môi trường toàn cầu. Trong những năm qua, nhiều nơi trên thế giới đã xảy ra những thiên tai nguy hiểm như bão lớn, nắng nóng dữ dội, lũ lụt, hạn hán, ... gây thiệt hại nặng nề về tính mạng con người và của cải vật chất. Vì vậy, việc tăng cường nhận thức và hành động trong nỗ lực ứng phó với biến đổi khí hậu đang trở thành một yêu cầu cấp thiết đối với toàn nhân loại cũng như mỗi quốc gia, mỗi vùng và mỗi người dân. Theo báo cáo của Ban Liên Chính phủ về biến đổi khí hậu (Intergovernmental Panel on Climate Change - IPCC), Việt Nam là một trong những quốc gia bị ảnh hưởng nghiêm trọng do tác động của biến đổi khí hậu. Đặc biệt, ba đồng bằng trên thế giới dễ bị tổn thương nhất do nước biển dâng là Đồng bằng sông Cửu Long (ĐBSCL) của Việt Nam, Đồng bằng sông Gange của Bangladesh và Đồng bằng sông Nile của Ai Cập (IPCC, 2007).

Như vậy, Cà Mau diện tích 5.294km². Nơi đây có hai hệ sinh thái rừng ngập mặn và ngập ngọt đại diện bởi Vườn Quốc gia Mũi Cà Mau và Vườn Quốc gia U Minh Hạ, được xếp vào Khu dự trữ sinh quyển thế giới. Đây là cơ sở để tỉnh phát triển du lịch sinh thái trải nghiệm, là điểm mạnh để lôi kéo ngành du lịch tỉnh phát triển mạnh đồng thời cũng chịu ảnh hưởng biến đổi khí hậu khá lớn và chịu tác động ngày càng mạnh mẽ, gây ra nhiều hậu quả nặng nề đối với mọi mặt kinh tế - xã hội (sạt lở đê bao, cháy rừng, lâm tặc, đã đến lúc báo động, ....), trong đó có ngành du lịch. Vì vậy, ngành du lịch nói chung và các doanh nghiệp, hộ gia đình, cá nhân kinh doanh du lịch nói riêng cần nâng cao nhận thức và chung tay hành động vì môi trường, chủ động ứng phó với biến đổi khí hậu và phát triển du lịch sinh thái trải nghiệm nhằm bảo vệ môi trường ngày càng tốt hơn trước tình hình khí hậu khắc nghiệt nước ta nói chung, nói riêng trên địa bàn tỉnh Cà Mau một cách có hiệu quả nhất.

Nghiên cứu này nhằm tìm hiểu "Các yếu tố tác động đến kinh doanh du lịch sinh thái trải nghiệm của hộ gia đình và cá nhân trên địa bàn tỉnh Cà Mau nhằm ứng phó với biến đổi khí hậu", từ đó, đề xuất một số giải pháp nâng cao nhận thức về kinh doanh du lịch sinh thái (DLST) trải nghiệm, góp phần phát triển du lịch sinh thái trải nghiệm bền vững ở tỉnh Cà Mau và góp phần bảo vệ hệ sinh thái rừng ngập mặn và ngập ngọt trên địa bàn tỉnh Cà Mau được tốt nhất.

\section{Cơ sở lý thuyết và mô hình nghiên cứu}

\subsection{Khái niệm du lịch sinh thái trải nghiệm}

Theo Hiệp hội DLST Hoa Kỳ, năm 1998 “DLST trải nghiệm là du lịch có mục đích với các khu tự nhiên, hiểu biết về lịch sử văn hóa và lịch sử tự nhiên của môi trường hòa mình vào 
với thiên nhiên, không làm biến đổi tình trạng của hệ sinh thái, đồng thời ta có cơ hội để phát triển kinh tế, bảo vệ nguồn tài nguyên thiên nhiên và lợi ích tài chính cho cộng đồng địa phương".

Một định nghĩa khác của (Honey, 1999) "DLST tự nhiên là du lịch hướng tới những khu vực nhạy cảm và nguyên sinh thường được bảo vệ với mục đích nhằm gây ra ít tác hại và với quy mô nhỏ nhất. Nó giúp giáo dục du khách, tạo quỹ để bảo vệ môi trường, nó trực tiếp đem lại nguồn lợi kinh tế và sự tự quản lý cho người dân địa phương và nó khuyến khích tôn trọng các giá trị về văn hóa và quyền con người”.

Ở Việt Nam vào năm 1999 trong khuôn khổ hội thảo xây dựng chiến lược quốc gia về phát triển du lịch sinh thái đã đưa ra định nghĩa như sau: "Du lịch sinh thái là hình thức du lịch thiên nhiên có mức độ giáo dục cao về sinh thái và môi trường có tác động tích cực đến việc bảo vệ môi trường và văn hóa, đảm bảo mang lại các lợi ích về tài chính cho cộng đồng địa phương và có đóng góp cho các nỗ lực bảo tồn".

\subsection{Cơ sở xây dụng mô hình nghiên cứu}

Sự tham gia của hộ gia đình vào hoạt động du lịch rất quan trọng, là điều kiện giúp cho du lịch của địa phương hoạt động và phát triển tốt. Trên thế giới đã có rất nhiều nghiên cứu về vấn đề này. Sự hỗ trợ của cộng đồng vào hoạt động du lịch sinh thái trải nghiệm bị tác động bởi các yếu tố, kinh tế, môi trường, văn hóa xã hội, nguồn lực của địa phương (Akarapong, Mingsarn, Vicente, Korawan, \& Javier, 2010; Dimitrios, Avital, Jason, \& Edith, 2014; Pam et al., 2007; Sun, 2013; Tsung, 2012; Yooshik, Dogan, \& Joseph, 2001). Mặt khác, nhận thức của cộng đồng đối với phát triển du lịch bị tác động bởi các yếu tố, kinh tế, văn hóa, xã hội, môi trường, chính quyền, chi phí cuộc sống và thái độ của người dân (Brida, Osti, \& Faccioli, 2011; Brida, Giacomo, Marta, \& Manuela, 2012; Subchat, 2013; Tatoglu, Erdal, Ozgur, \& Azakli, 2002; Zhang, 2009 và Mohd et al., 2013). Bên cạnh đó, sự sẵn lòng tham gia vào hoạt động du lịch sinh thái của hộ gia đình và cá nhân cũng được nhiều nhà nghiên cứu thực hiện. Theo (Tang, Zhong, \& Cheng, 2012), các nhân tố kinh tế, văn hóa xã hội, nguồn lực địa phương và môi trường; (Huamin \& Xuejing, 2011), các nhân tố kinh tế, chính quyền, nguồn lực địa phương và môi trường; (Rojana, 2013) các nhân tố, phúc lợi địa phương, văn hóa xã hội và chính quyền cơ sở; (Rukavina, Soemarno, Luchman, \& Iwan, 2013) và (Do, Bui, \& Nguyen, 2016) các nhân tố, vốn xã hội, chính quyền và quy luật là có ảnh hưởng đến sự sã̃n lòng tham gia vào hoạt động du lịch sinh thái của hộ gia đình. Trên cơ sở đó, tác giả đề xuất mô hình nghiên cứu: Các yếu tố tác động đến kinh doanh du lịch sinh thái trải nghiệm của hộ gia đình và cá nhân trên địa bàn tỉnh Cà Mau nhằm ứng phó biến đổi khí hậu được cụ thể hóa như Hình 1. 


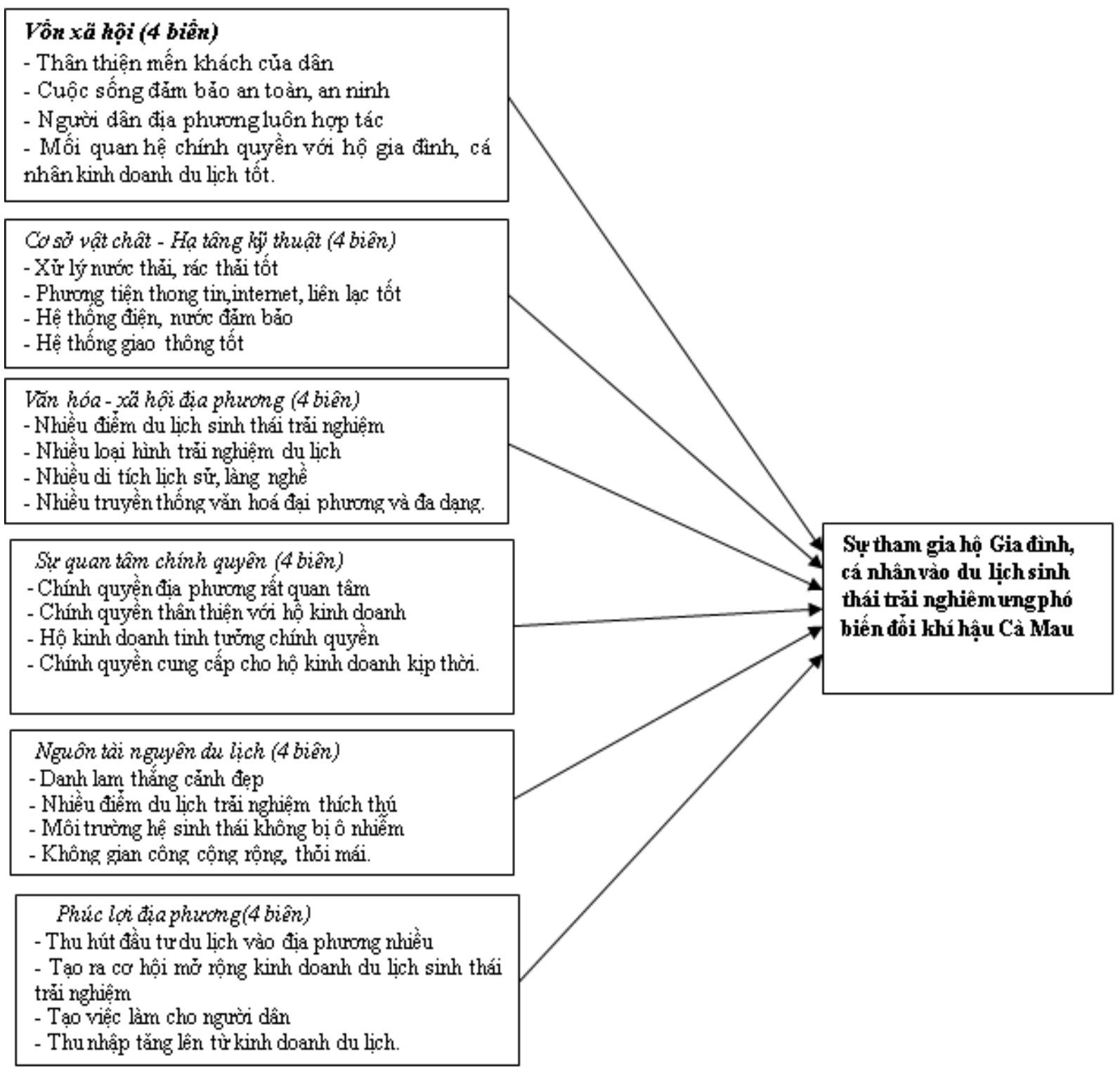

Hình 1. Mô hình nghiên cứu đề xuất

Vốn $x \tilde{a} \boldsymbol{h}$ họi: thể hiện thông qua các mối quan hệ của hộ gia đình, cá nhân kinh doanh du lịch với những tác nhân khác trong hoạt động du lịch. (Rojana, 2013) cho rằng, vốn xã hội là một yếu tố quan trọng khuyến khích sự tham gia của hộ gia đình, vì khi hộ gia đình tham gia du lịch sẽ tồn tại nhiều khó khăn như: nguồn vốn, kỹ năng chuyên môn và việc quảng bá tiếp thị, nhưng nếu có quan hệ tốt với các tác nhân khác sẽ thuận lợi hơn trong việc giải quyết những khó khăn. Chính vì thế, nếu hộ gia đình có mối quan hệ tốt với các tác nhân khác, sẽ tạo điều kiện cho hoạt động du lịch tốt hơn, góp phần làm tăng sự tham gia của hộ gia đình, cá nhân vào hoạt động du lịch.

Co sở vật chất - Hạ tầng $k \tilde{y}$ thuật: là những cơ sở vật chất của địa phương, đóng góp vào việc hình thành và phát triển du lịch. Theo (Akarapong et al., 2010) địa phương có du lịch phát triển cần có những điều kiện về cơ sở hạ tầng, giao thông tốt... Do đó, nếu địa phương có điều kiện về cơ sở vật chất tốt, sẽ góp phần cho hoạt động du lịch có chất lượng hơn. Điều này 
dẫn đến, có nhiều thuận lợi hơn cho các hộ gia đình, cá nhân khi tham gia vào hoạt động du lịch.

Văn hóa - xã hội địa phưong: là những nét văn hóa và di tích lịch sử ở địa phương, điều này góp phần làm tăng thêm giá trị cho địa điểm du lịch, thu hút khách du lịch. Theo (Yooshik et al., 2001), văn hóa - xã hội địa phương góp phần tạo ra nhiều lợi ích, giúp cho du lịch ở địa phương phát triển. Qua đó, văn hóa - xã hội địa phương cũng sẽ có những đóng góp, khuyến khích sự tham gia của hộ gia đình vào hoạt động du lịch sinh thái. Cà Mau có rất nhiều di sản văn hóa địa phương, nếu phát huy tốt các di sản sẽ tác động lớn đến việc thu hút du khách đến với Cà Mau (Truyện cười Nguyễn Long Phi (Bác Ba Phi), lễ nghinh ông, làng dệt chiếu Tân Thành, làng nuôi cá Bống Tượng, ...)

Sục quan tâm chính quyền: là những hỗ trợ từ chính quyền địa phương đến những hộ gia đình, cá nhân tham gia vào hoạt động du lịch sinh thái trải nghiệm. Theo đó, chính sách địa phương rất quan trọng, tạo điều kiện để các tác nhân phục vụ du lịch liên kết và tham gia vào du lịch (Rojana, 2013). Bên cạnh đó, chính sách sẽ góp phần cho việc phát triển du lịch, dẫn đến khuyến khích sự tham gia của hộ gia đình, cá nhân vào hoạt động du lịch (Huamin \& Xuejing, 2011). Chính vì thế, chính sách địa phương được cho là một yếu tố khuyến khích các hộ gia đình, cá nhân tham gia vào hoạt động du lịch. Nếu sự phối hợp giữa chính quyền và người dân tốt, nó sẽ tác động đến nhiều yếu tố khác tăng lên ví dụ như Giảm tỷ lệ ô nhiễm môi trường, giảm tệ nạn xã hội, tạo công ăn việc làm, tăng trưởng kinh tế địa phương...

Nguồn tài nguyên du lịch: Một địa điểm du lịch có thể phát triển hay không phụ thuộc rất nhiều vào điều kiện môi trường tự nhiên. Theo (May et al., 2013), môi trường tự nhiên cần được đặc biệt chú trọng, vì môi trường tự nhiên là sự cần thiết cho sự phát triển du lịch sinh thái bền vững. Do đó, nếu địa phương có điều kiện môi trường tự nhiên thích hợp, sẽ tạo nhiều thuận lợi cho hoạt động du lịch phát triển. Dẫn đến, khuyến khích sự tham gia của các hộ gia đình và cá nhân vào hoạt động du lịch. Bởi kinh doanh du lịch phát triển thì sự cạnh tranh chất lượng dịch vụ diễn ra, lúc đó hộ gia đình cá nhân mới tác động đến sinh cảnh tự nhiên, họ sẽ bảo vệ thiên nhiên, bảo vệ màu xanh của rừng, của biển và hệ sinh thái tự nhiên.

Phúc lọi địa phương: Là những lợi ích về mặt kinh tế mà hộ gia đình, cá nhân nhận được khi tham gia vào hoạt động du lịch sinh thái trải nghiệm. Theo (Tosun, 2000) và (May et al., 2013), lợi ích là một trong những tác động chính dẫn đến sự tham gia vào du lịch của hộ gia đình và cá nhân làm du lịch. Bên cạnh đó, (Rojana, 2013) cho rằng, phúc lợi địa phương là một yếu tố không thể thiếu khi tham gia vào hoạt động du lịch, đặc biệt là ở các nước đang phát triển, nó là động lực ban đầu khuyến khích sự tham gia của hộ gia đình vào du lịch. Chính vì thế, phúc lợi địa phương sẽ góp phần tác động đến sự tham gia của hộ gia đình và cá nhân vào hoạt động du lịch. Nếu sự chung tay của hộ gia đình, cá nhân nâng cao được ý thức cải thiện màu xanh của rừng, biển, hệ sinh thái... sẽ có tác động rất lớn vào việc ứng phó với biến đổi khí hậu hiệu quả. 


\section{Phương pháp nghiên cứu}

\subsection{Thu thập số liệu thứ cấp}

Số liệu thứ cấp được thu thập từ các báo cáo, thông tin của các cơ quan Nhà nước như: Ủy ban nhân dân (UBND) tỉnh Cà Mau, Cục thống kê tỉnh Cà Mau, Sở Văn hóa - Thể thao và Du lịch, Trung tâm Xúc tiến Thương mại Du lịch và Đầu tư tỉnh Cà Mau và các Báo cáo ngành Du lịch 2015 - 2016; ngoài ra còn thu thập số liệu thứ cấp từ sách, báo, internet, các bài nghiên cứu và chuyên đề khác để phục vụ cho nghiên cứu.

\subsection{Thu thập số liệu sơ cấp}

Số liệu sơ cấp được thu thập bằng cách phỏng vấn trực tiếp các hộ gia đình, cá nhân kinh doanh du lịch sinh thái trải nghiệm trên địa bàn tỉnh Cà Mau (Khu du lịch Tân Tây Nam thuộc xã Hòa Thành; Khu du lịch sinh thái trải nghiệm Đầm Thị Tường - Huyện Phú Tân; Khu Du lịch Biển Khai Long - Huyện Ngọc Hiển; Khu Du lịch Đất Mũi - Huyện Năm Căn; Vườn quốc gia U Minh Hạ - Huyện Trần Văn Thời, Khu du lịch Hòn Đá Bạc - Huyện Trần Văn Thời...), các nhà quản lý trong ngành du lịch tại các địa điểm có hoạt động du lịch trên địa bàn tỉnh Cà Mau thông qua bảng câu hỏi thiết kế sẵn. Thực hiện khảo sát từ tháng 2-5/2017.

Cõ̃ mẫu: Cỡ mẫu của nghiên cứu được xác định theo Giáo trình Quản trị tiếp thị của (Luu, 2007). Thông thường, các nghiên cứu trong thực tế nhà nghiên cứu mặc nhiên sử dụng cỡ mẫu bằng hoặc lớn hơn 100, mà không cần tính toán cỡ mẫu, vì cỡ mẫu này đã thuộc loại lớn bảo đảm cho tính suy rộng hoặc theo (Hair, Black, Babin, Anderson, \& Tatham, 2006), trong kích thước mẫu càng lớn càng tốt. Đối với phân tích nhân tố khám phá thì tỷ lệ mẫu và biến quan sát là $5: 1$ có nghĩa là 1 biến đo lường cần tối thiểu là 5 quan sát trong nghiên cứu sử dụng 24 biến để đo lường vậy $24 * 5=120$ quan sát. Tuy nhiên, tác giả chọn cỡ mẫu của nghiên cứu là 130 quan sát (Thực tế số bảng câu hỏi phát ra phòng ngừa các bảng hỏi bị sai sót nên ta lấy 130 bảng hỏi).

\section{Bảng 1}

Mô tả mẫu điều tra theo đối tượng kinh doanh

\begin{tabular}{clcc}
\hline STT & \multicolumn{1}{c}{ Ngành nghề } & Quan sát & Tỷ lệ \\
\hline 1 & $\begin{array}{l}\text { Hộ kinh doanh du lịch trải nghiệm } \\
\text { Cá nhân tham gia du lịch và vận chuyển } \\
\text { khách tham quan bằng phương tiện địa } \\
\text { phương }\end{array}$ & 60 & 46,16 \\
& $\begin{array}{l}\text { Hộ gia đình, cá nhân phục vụ thực phẩm trải } \\
\text { nghiệm (Bắt tôm, chày cá, câu cá, bắt } \\
\text { sò........) }\end{array}$ & 22 & 16,39 \\
4 & $\begin{array}{l}\text { Hộ gia đình, cá nhân kinh doanh sản phẩm } \\
\text { du lịch (Tôm khô, mực, cua, cá......) }\end{array}$ & 15 & 11,53 \\
5 & Tổng quan sát & $\mathbf{1 3 0}$ & $\mathbf{1 0 0 , 0 0}$ \\
\hline
\end{tabular}

Nguồn: Kết quả phân tích dữ liệu của nhóm nghiên cứu 
Phương pháp chọn mẫu: Do không có danh sách hay số lượng hộ gia đình, cá nhân tham gia vào hoạt động kinh doanh du lịch sinh thái trải nghiệm cụ thể. Thêm vào đó, hệ thống giao thông chằng chịt rất khó tiếp cận đối tượng khảo sát. Chính vì thế, nhóm tác giả đến khảo sát tại những điểm du lịch dễ dàng tiếp cận, sau đó nhờ họ giới thiệu thêm những điểm du lịch khác. Do đó, số liệu được thu thập theo phương pháp thuận tiện.

\subsection{Phương pháp nhập và phân tích số liệu}

Việc xác định các nhân tố ảnh hưởng đến sự tham gia của hộ gia đình, cá nhân vào hoạt động du lịch sinh thái trải nghiệm được thực hiện thông qua các bước:

Bước 1, sử dụng hệ số Cronbach's Alpha để kiểm định mức độ chặt chẽ của các biến quan sát, những biến không đảm bảo độ tin cậy sẽ bị loại khỏi mô hình nghiên cứu.

Bước 2, sử dụng phương pháp phân tích nhân tố khám phá để kiểm định các nhân tố ảnh hưởng và nhận diện các nhân tố được cho là ảnh hưởng đến sự tham gia của hộ gia đình.

Bước 3, sử dụng phương pháp tính điểm trung bình và xếp hạng mức độ ảnh hưởng của các nhân tố đến sự tham gia của hộ gia đình, cá nhân vào hoạt động du lịch vườn sinh thái trải nghiệm. Tác giả sử dụng phần mềm Microsoft Excel 2007 và SPSS 20.0 để nhập và phân tích dữ liệu.

\section{Kết quả nghiên cứu và thảo luận}

\subsection{Kết quả phân tích}

\section{Bước 1: Đánh giá độ tin cậy thông qua hệ số Cronbach's Alpha}

Bộ tiêu chí gồm 24 biến là nhận định của các hộ gia đình và cá nhân đã tham gia vào hoạt động phục vụ du lịch như: Vốn xã hội, cơ sở vật chất - Hạ tầng kỹ thuật, Văn hóa - xã hội địa phương, sự quan tâm chính quyền, nguồn tài nguyên du lịch, phúc lợi địa phương. Tất cả đều đo lường bằng thang đo Likert 5 mức độ, thông qua đánh giá của đáp viên từ: $1:$ Rất không đồng ý; 2: Không đồng ý; 3: Trung lập; 4: Đồng ý; 5: Rất đồng ý.

\section{Bảng 1}

Kết quả kiểm định thang đo

\begin{tabular}{lcc}
\hline \multicolumn{1}{c}{ Nhân tố } & $\begin{array}{c}\text { Hệ số tương quan biến tổng } \\
\text { Cronbach's } \boldsymbol{A l p h a} \mathbf{= 0 , 8 9 7}\end{array}$ & Cronbach's Alpha \\
\hline SQTCQ1 & 0,358 & 0,897 \\
SQTCQ2 & 0,401 & 0,896 \\
SQTCQ3 & 0,587 & 0,888 \\
SQTCQ4 & 0,560 & 0,891 \\
CSVC-HTKT1 & 0,468 & 0,893 \\
CSVC-HTKT2 & 0,525 & 0,891 \\
CSVC-HTKT3 & 0,424 & 0,894 \\
CSVC-HTKT4 & 0,378 & 0,895 \\
NTNDL1 & 0,560 & 0,890 \\
NTNDL2 & 0,580 & 0,890 \\
NTNDL3 & 0,631 & 0,888 \\
\hline
\end{tabular}




\begin{tabular}{lcc}
\hline Nhân tố & $\begin{array}{c}\text { Hệ số tương quan biến tổng } \\
\text { Cronbach's } \boldsymbol{A l p h a} \boldsymbol{\mathbf { 0 }} \mathbf{0 , 8 9 7}\end{array}$ & Cronbach's Alpha \\
\hline VHXHĐP1 & 0,358 & 0,895 \\
VHXHĐP2 & 0,476 & 0,893 \\
VHXHĐP3 & 0,561 & 0,892 \\
VHXHĐP4 & 0,423 & 0,893 \\
VXH1 & 0,568 & 0,890 \\
VXH2 & 0,672 & 0,887 \\
VXH3 & 0,609 & 0,889 \\
VXH4 & 0,651 & 0,888 \\
PLĐP1 & 0,308 & 0,896 \\
PLĐP2 & 0,585 & 0,890 \\
PLĐP3 & 0,534 & 0,892 \\
\hline
\end{tabular}

Nguồn: Số liệu điều tra, 2016

Thang đo sẽ được chọn nếu hệ số Cronbach's Alpha > 0,6 (Nunnally \& Bernstein, 1994). Kết quả kiểm định cho thấy, hệ số Cronbach's Alpha đạt 0,897 nằm trong khoảng từ 0,8 đến 1 chứng tỏ thang đo lường là tốt. Tuy nhiên, hệ số tương quan biến tổng < 0,3 sẽ bị loại khỏi mô hình nghiên cứu (Nunnally, 1978; Peterson, 1994; Slater, 1995). Do đó, có 2 biến bị loại khỏi mô hình là phúc lợi địa phương $(\mathrm{PLĐP} 4=0,285)$ và biến nguồn tài nguyên du lịch (NTNDL4 = 0.297) trong bảng phân tích Cronbach's Alpha lần 1. Vì vậy, còn lại 22 biến quan sát được sử dụng trong phân tích nhân tố khám phá tiếp theo.

\section{Bước 2: Kết quả phân tích nhân tố khám phá EFA}

Giá trị của 2 kiểm định $\mathrm{KMO}$ và Bartlett's dùng để kiểm định sự phù hợp và sự tương quan giữa các biến. Giá trị $\mathrm{KMO}=0,827$ nằm trong khoảng từ 0,5 đến 1 điều này chứng tỏ phân tích nhân tố khám phá là phù hợp (Hair et al., 2006); trong kiểm định Bartlett's giá trị Sig. = $0,000<0,05$ điều này thể hiện các biến có tương quan với nhau trong tổng thể (Hoàng Trọng và Chu Nguyễn Mộng Ngọc, 2008). Giá trị tổng phương sai trích =69,728\% (>50\%) đạt yêu cầu (Gerbing \& Anderson, 1987; Hair et al., 2006), điều này cho thấy các biến quan sát giải thích được 69,728\% độ biến thiên của dữ liệu. Theo (Hair, Anderson, Tatham, \& Black, 1998) hệ số tải nhân tố là chỉ tiêu đảm bảo mức ý nghĩa thiết thực của EFA, hệ số tải nhân tố $>0,3$ được xem là đạt được mức tối thiểu và cỡ mẫu nên chọn ít nhất phải đảm bảo phù hợp, hệ số tải nhân tố $>0,4$ được xem là quan trọng, nếu cỡ mẫu khoảng 100 thì hệ số tải nhân tố $>0,5$ được xem là có ý nghĩa thực tiê̂n.

\section{Bảng 3}

Kết quả ma trận xoay

\begin{tabular}{lccccc}
\hline \multicolumn{1}{c}{ Nhân tố } & \multicolumn{5}{c}{ Hệ số tải nhân tố } \\
& F1 & F2 & F3 & F4 & F5 \\
\hline SQTCQ1 & 0,787 & 0,129 & $-0,123$ & $-0,060$ & 0,124 \\
SQTCQ2 & 0,828 & 0,168 & $-0,075$ & $-0,054$ & 0,060 \\
SQTCQ3 & 0,817 & 0,145 & 0,138 & 0,180 & 0,117 \\
SQTCQ4 & 0,777 & 0,253 & 0,053 & 0,149 & 0,078
\end{tabular}




\begin{tabular}{llcccc}
\hline \multicolumn{1}{c}{ Nhân tố } & \multicolumn{5}{c}{ Hệ số tải nhân tố } \\
& $\mathbf{F 1}$ & $\mathbf{F 2}$ & $\mathbf{F 3}$ & $\mathbf{F 4}$ & F5 \\
\hline CSVC-HTKT1 & 0,066 & 0,082 & 0,435 & 0,679 & $-0,027$ \\
CSVC-HTKT2 & 0,125 & 0,191 & 0,109 & 0,842 & 0,111 \\
CSVC-HTKT3 & 0,106 & 0,043 & 0,068 & 0,833 & 0,156 \\
CSVC-HTKT4 & $-0,021$ & 0,205 & 0,089 & 0,720 & 0,043 \\
NTNDL1 & 0,166 & 0,716 & $-0,079$ & 0,239 & 0,291 \\
NTNDL2 & 0,247 & 0,716 & 0,045 & 0,230 & 0,140 \\
NTNDL3 & $-0,020$ & 0,046 & 0,779 & 0,091 & 0,099 \\
VHXHĐP1 & 0,151 & 0,011 & 0,792 & 0,075 & 0,274 \\
VHXHĐP2 & 0,026 & 0,405 & 0,644 & 0,142 & 0,101 \\
VHXHĐP3 & $-0,055$ & 0,194 & 0,736 & 0,197 & $-0,010$ \\
VHXHĐP4 & 0,577 & 0,206 & 0,396 & 0,198 & $-0,054$ \\
VXH1 & 0,336 & 0,742 & 0,285 & 0,101 & $-0,038$ \\
VXH2 & 0,061 & 0,797 & 0,275 & 0,080 & 0,135 \\
VXH3 & 0,288 & 0,745 & 0,155 & 0,057 & 0,217 \\
VXH4 & $-0,049$ & 0,161 & $-0,047$ & 0,187 & 0,744 \\
PLĐP1 & 0,153 & 0,271 & 0,289 & 0,071 & 0,788 \\
PLĐP2 & 0,321 & 0,134 & 0,285 & 0,004 & 0,703 \\
PLĐP3 & & & & 1,301 \\
\hline Lượng biến thiên được giải thích bởi nhân tố & 2,718 & 1,797 & & $\mathbf{6 9}, 728$ \\
Tồng phương sai trích & & & & & \\
\hline
\end{tabular}

Nguồn: Kết quả xử lý từ dữ liệu điều tra

Kết quả phân tích nhân tố lần 2 thực hiện được thể hiện trong Bảng 3 , sau phân tích nhân tố lần 1 có 2 biến bị loại khỏi mô hình là phúc lợi địa phương (PLĐP4 = 0,285) và biến nguồn tài nguyên du lịch (NTNDL4 = 0.297) đã bị loại khỏi mô hình nghiên cứu do có hệ tải nhân tố không thỏa điều kiện <0,5. Các biến còn lại được tiến hành phân tích nhân tố lần 2 đều có hệ số tải nhân tố $>0,5$ do đó không có biến nào loại khỏi mô hình nghiên cứu. Kết quả nghiên cứu cho thấy, các biến được rút trích thành 5 nhóm, bao gồm: F1: Sự quan tâm chính quyền (SQTCQ1, SQTCQ2, SQTCQ3, SQTCQ4, VXH1); F2: Nguồn tài nguyên du lịch và vốn xã hội (NTNDL2, NTNDL3, VXH2, VXH3, VXH4); F3: văn hóa xã hội địa phương (VHXHĐP1, VHXHĐP2, VHXHĐP3, VHXHĐP4); F4: Cơ sở vật chất - Hạ tầng kỹ thuật (CSVT-HTKT1, CSVT-HTKT2, CSVT-HTKT3, CSVT-HTKT4); F5: phúc lợi địa phương (LI1, LI2, LI3).

\section{Bước 3: Mức độ ảnh hưởng của các nhân tố}

Với kết quả phân tích nhân tố khám phá ở bước 3, cho thấy các biến quan sát được rút trích thành 5 yếu tố, bao gồm: $\mathrm{F} 1$ : chính sách địa phương, $\mathrm{F} 2$ : môi trường tự nhiên và vốn xã hội, F3: văn hóa xã hội, F4: nguồn lực địa phương, F5: lợi ích kinh tế. Như vậy, có 5 nhóm yếu tố tác động đến sự tham gia của hộ gia đình vào hoạt động du lịch vườn sinh thái. Mức độ tác động của từng nhóm nhân tố đến sự tham gia của hộ gia đình được thể hiện ở Bảng 4 dưới đây. 


\subsection{Thảo luận kết quả phân tích}

Theo kết quả phân tích, nhóm nhân tố "phúc lợi địa phưong” là biến tác động mạnh nhất đến sự tham gia của hộ gia đình, cá nhân vào hoạt động du lịch sinh thái trải nghiệm, có điểm trung bình là 4,22. Trong mọi hoạt động sản xuất kinh doanh, phúc lợi địa phương luôn là mối quan tâm hàng đầu của người đầu tư kinh doanh du lịch của từng hộ gia đình và cá nhân khi tham gia du lịch. Kết quả này cũng tương xứng với kết quả các nghiên cứu đã lược khảo, lợi ích kinh tế là một yếu tố quan trọng khuyến khích sự tham gia của hộ gia đình, cá nhân vào hoạt động du lịch sinh thái trải nghiệm. Mặc dù nhận được phúc lợi địa phương, nhưng chưa thật sự tương xứng với tiềm năng mà du lịch địa phương mang lại. Do không có sản phẩm du lịch đặc trưng và chưa có chiến lược Marketing quảng bá sản phẩm du lịch, Cà mau cần thiết phải thực hiện Marketing du lịch rộng rãi về du lịch sinh thái trải nghiệm, du lịch sinh thái trải nghiệm chưa đa dạng, phong phú, cho nên lượng khách du lịch chưa nhiều và có tính thời vụ.

\section{Bảng 4}

Mức độ ảnh hưởng của các nhân tố

\begin{tabular}{|c|c|c|c|}
\hline Nhân tố & Độ lệch chuẩn & Giá trị trung bình & Xếp hạng \\
\hline Phúc lợ địa phương & & Giá trị trung bình $=4,22$ & \\
\hline PLĐP1 & 0,901 & 3,81 & \\
\hline PLĐP2 & 0,799 & 4,58 & 1 \\
\hline PLĐP3 & 0,781 & 4,29 & \\
\hline Nguồn tài nguyên du lịch và vốn xã hội & & Giá trị trung bình = 3,87 & \\
\hline NTNDL2 & 1,242 & 3,70 & \\
\hline NTNDL3 & 1,292 & 3,68 & \\
\hline VXH2 & 1,152 & 4,21 & 2 \\
\hline VXH3 & 1,119 & 4,06 & \\
\hline VXH4 & 1,137 & 3,72 & \\
\hline Sự quan tâm chính quyền & & Giá trị trung bình = 3,65 & \\
\hline SQTCQ1 & 1,248 & 3,78 & 3 \\
\hline SQTCQ2 & 1,000 & 3,85 & \\
\hline SQTCQ3 & 0,904 & 3,71 & \\
\hline SQTCQ4 & 1,162 & 3,26 & \\
\hline Văn hóa xã hội địa phuoong & & Giá trị trung bình = 3,61 & \\
\hline VHXHĐP1 & 1,174 & 3,81 & \\
\hline VHXHĐP2 & 1,157 & 3,72 & 4 \\
\hline VHXHĐP3 & 0,938 & 3,64 & \\
\hline VHXHĐP4 & 1,1074 & 3,30 & \\
\hline
\end{tabular}


Nhân tố

Độ lệch chuẩn

Giá trị trung bình

Xếp hạng

Co sở vật chất- Hạ tâng kỹ thuật - VXH

CSVC-HTKT1

1,338

Giá trị trung bình = 3,10

CSVC-HTKT2

1,275

2,38

2,67

5

CSVC-HTKT3

1,195

3,38

CSVC-HTKT4

1,092

3,48

VXH1

1,201

1,201

Thang đo Likert: 1: Rất không đồng ý; 2: Không đồng ý; 3: Trung lập; 4: Đồng ý; 5: Rất đồng ý Nguồn: số liệu điều tra, 2016

Nhóm nhân tố "Nguồn tài nguyên du lịch và vốn xã hội" có điểm trung bình là 3,87 . Điều này cho thấy, khi địa phương có điều kiện nguồn tài nguyên du lịch phong phú và hộ gia đình và cá nhân có mối quan hệ tốt với các tác nhân liên quan thì sự tham gia của hộ gia đình, cá nhân sẽ được gia tăng. Thật vậy, đối với loại hình du lịch sinh thái trải nghiệm, nguồn tài nguyên du lịch là một yếu tố quan trọng quyết định sự bền vững của hoạt động du lịch. Cà Mau có lợi thế hai khu sinh quyển được thế giới công nhận là Mũi Cà Mau và Vườn quốc gia $U$ Minh Hạ, đồng thời có diện tích đất nông nghiệp phát triển mạnh cho nên hội đủ điều kiện tự nhiên để thực hiện hoạt động du lịch vườn sinh thái trải nghiệm. Hơn thế, khi có mối quan hệ tốt với các tác nhân liên quan như: công ty du lịch, chính quyền địa phương, người dân, ... Thực tế, các hộ gia đình và cá nhân luôn tạo điều kiện tốt với chính quyền địa phương và công ty du lịch, người dân trong vùng rất thân thiện và gần gũi, điều này cũng góp phần tạo điều kiện thuận lợi cho hoạt động du lịch của hộ gia đình.

Nhân tố "Sự quan tâm của chính quyền", được đánh giá ở mức điểm trung bình là 3,65. Khi cơ sở vật chất của địa phương tốt, sẽ tạo điều kiện cho hoạt động du lịch sinh thái trải nghiệm diễn ra thuận lợi. Do đó, khi địa phương có cơ sở vật chất tốt, cũng sẽ góp phần khuyến khích sự tham gia của hộ gia đình, cá nhân vào hoạt động du lịch sinh thái trải nghiệm tốt. Tuy nhiên, cơ sở vật chất của địa phương cũng cần phải cải thiện rất nhiều về hệ thống giao thông, hệ thống cung cấp điện và nước để góp phần phát triển loại hình du lịch vườn sinh thái.

Nhân tố “Văn hóa xã hội địa phương” có điểm trung bình là 3,61 ở mức quan trọng. Tỉnh Cà Mau thế mạnh là thủy sản, nông nghiệp, nên có hệ thống sông ngòi chằng chịt với nét văn hóa đậm chất miền Tây Nam Bộ. Bên cạnh đó, có nhiều điểm du lịch tâm sinh thái và di tích lịch sử như: Khu du lịch Tân Tây Nam thuộc xã Hoà Thành; Khu du sinh thái trải nghiệm Đầm Thị Tường - Huyện Phú Tân; Khu Du lịch Biển Khai Long - Huyện Ngọc Hiển; Khu Du lịch Đất Mũi - Huyện Năm Căn; Vườn quốc gia U Minh Hạ - Huyện Trần Văn Thời, Khu du lịch Hòn Đá Bạc - Huyện Trần Văn Thời... Chính vì thế, đây là một yếu tố quan trọng ảnh hưởng đến sự tham gia của hộ gia đình, cá nhân vào hoạt động du lịch sinh thái trải nghiệm.

Cuối cùng là nhân tố “Cơ sở vật chất-Hạ tầng kỹ thuật - vốn xã hội”, được đánh giá ở mức điểm trung bình là 3,10 (Thấp nhất). Khi cơ sở vật chất của địa phương tốt, sẽ tạo điều kiện cho hoạt động du lịch vườn sinh thái trải nghiệm diễn ra thuận lợi. Do đó, khi địa phương 
có cơ sở vật chất tốt, cũng sẽ góp phần khuyến khích sự tham gia của hộ gia đình, cá nhân vào hoạt động du lịch sinh thái trải nghiệm. Tuy nhiên, cơ sở vật chất - Hạ tầng kỹ thuật của Cà Mau để đi đến từng hộ gia đình, cá nhân kinh doanh chưa hài lòng ở mức độ rất thấp, Nhà nước cần quan tâm hơn về hạ tầng giao thông, để thuận tiện cho hộ gia đình, cá nhân tham gia kinh doanh du lịch đồng thời đầu tư hệ thống cung cấp điện và nước để góp phần phát triển loại hình du lịch sinh thái trải nghiệm Cà Mau tốt hơn.

\section{Kết luận và đề xuất}

Thông qua việc xác định các nhân tố ảnh hưởng đến sự tham gia của hộ gia đình, cá nhân vào hoạt động du lịch sinh thái trải nghiệm, kết quả nghiên cứu chỉ ra có 5 yếu tố tác động, đó là F1: Sự quan tâm chính quyền (SQTCQ1, SQTCQ2, SQTCQ3, SQTCQ4, VXH1); F2: Nguồn tài nguyên du lịch và vốn xã hội (NTNDL2, NTNDL3, VXH2, VXH3, VXH4); F3: văn hóa xã hội địa phương (VHXHĐP1, VHXHĐP2, VHXHĐP3, VHXHĐP4); F4: Cơ sở vật chất - Hạ tầng kỹ thuật (CSVT-HTKT1, CSVT-HTKT2, CSVT-HTKT3, CSVT-HTKT4); F5: phúc lợi địa phương (LI1, LI2, LI3). Mỗi nhóm yếu tố đều có những đóng góp tích cực, góp phần làm tăng sự tham gia của hộ gia đình, cá nhân vào hoạt động du lịch sinh thái trải nghiệm. Tuy nhiên, cũng tồn tại nhiều hạn chế làm cho hoạt động du lịch sinh thái trải nghiệm ở địa phương gặp nhiều khó khăn cần khắc phục.

Cơ quan quản lý du lịch và hộ gia đình, cá nhân: Khi kinh doanh du lịch cần tiếp tục nâng cao nhận thức về môi trường và biến đổi khí hậu đối với các doanh nghiệp lưu trú du lịch là một yêu cầu cấp thiết, nhất là việc cung cấp các kiến thức chuyên ngành như: vấn đề tác động của biến đổi khí hậu đối với du lịch, vấn đề phát triển du lịch sinh thái trải nghiệm, vấn đề áp dụng nhãn sinh thái trong du lịch, ... nhằm đẩy mạnh phát triển du lịch xanh, bền vững trên địa bàn tỉnh Cà Mau. Bởi vì khi tham gia khai thác du lịch là tác động đến hệ sinh thái xanh và hệ sinh thái sinh học, cần thiết hộ gia đình phải trồng thêm rừng, bảo vệ chắn sống, ngăn ngừa được lục bão, gió lốc... Đẩy mạnh công tác tuyên truyền giáo dục trong ngành du lịch để nâng cao nhận thức về môi trường và biến đổi khí hậu. Đặc biệt là việc tuyên truyền, phổ biến và triển khai áp dụng Nhãn du lịch bền vững Bông sen xanh, làm cho các doanh nghiệp thấy rõ ý nghĩa và sự cần thiết áp dụng nhãn sinh thái này để nâng cao chất lượng dịch vụ lưu trú và bảo đảm phát triển du lịch sinh thái trải nghiệm bền vững.

Đối với hộ gia đình, cá nhân, nếu muốn tăng nguồn thu nhập, hộ gia đình cần cải thiện các dịch vụ để thu hút khách du lịch. Đối với các hộ kinh doanh thực phẩm, cần cải thiện món ăn đa dạng, thiết kế các trò vui chơi giải trí trải nghiệm mới lạ. Đối với hộ vận chuyển, phải trang bị phao cứu hộ trên phương tiện vận chuyển, nhằm đảm bảo an toàn cho du khách. Đối với hộ kinh doanh sản phẩm du lịch, cần sáng tạo thiết kế ra những sản phẩm mới, đặc trưng, khó tìm thấy ở những điểm du lịch khác. Mặt khác, các hộ gia đình, cá nhân tham gia du lịch cần có sự liên kết, hỗ trợ giữa các tác nhân khác nhằm giúp du lịch sinh thái trải nghiệm phát triển. Bên cạnh đó, cần trang bị ngoại ngữ cho nguồn nhân lực tham gia phát triển du lịch sinh thái trải nghiệm.

Đối với chính quyền, chính quyền cần chủ động tìm hướng thu hút khách du lịch như: nâng cao lượng khách du lịch (thu hút sinh viên quốc tế và khách du lịch đến nghỉ đông), tăng cường quảng bá du lịch sinh thái trải nghiệm qua nhiều kênh (truyền hình, hội trợ, triễn lãm du 
lịch, Internet, Marketing du lịch, phim ảnh, MV ca nhạc, đại sứ du lịch). Giải quyết những khó khăn về hệ thống giao thông như: đầu tư cải thiện hệ thống giao thông đường bộ, thành lập điểm phụ trợ nhằm vận chuyển khách du lịch đến điểm sinh thái trải nghiệm bằng đường thủy hoặc đường hộ, hình thành loại hình du lịch đặc trưng miền sông nước Cà Mau. Chính quyền cần tăng cường hỗ trợ đối với hộ gia đình, cá nhân tham gia du lịch về vốn, chủ động kết nối các tác nhân phát triển du lịch sinh thái trải nghiệm.

Hạn chế và hướng nghiên cúu tiếp theo, để du lịch sinh thái trải nghiệm phát triển cần sự tham gia của nhiều tác nhân. Các tác nhân tham gia vào hoạt động du lịch sinh thái trải nghiệm có thể bao gồm: chính quyền, công ty du lịch, nhà hàng khách sạn, hộ gia đình phục vụ du lịch, ... Tuy nhiên, nghiên cứu chỉ dừng lại ở đối tượng là hộ gia đình, cá nhân phục vụ du lịch sinh thái trải nghiệm, chưa xem xét sự tham gia của các tác nhân khác vào hoạt động du lịch sinh thái trải nghiệm. Đó là hạn chế và cũng là hướng cần thực hiện các nghiên cứu tiếp theo, giúp phát triển du lịch sinh thái trải nghiệm trên địa bàn tỉnh Cà Mau.

\section{Tài liệu tham khảo}

Akarapong, U., Mingsarn, K., Vicente, R., Korawan, S., \& Javier, R. M. (2010). Factors influencing local resident support for tourism development: A structural equation model. Paper presented at the Best Paper Award in the APTA Conference 2010 at Macau, China.

Bộ Tài nguyên và Môi trường. (2012). Kịch bản biến đổi khi hậu, nước biển dâng cho Việt Nam [Climate change and sea level rise scenarios for Vietnam]. Hanoi, Vietnam: NXB Tài nguyên - Môi trường và Bản đồ Việt Nam.

Bộ Văn hoá, Thể thao và Du lịch. (2012). Bộ tiêu chí Nhãn du lịch bền vũng Bông sen xanh áp dụng đối với co sở lưu trú du lịch tại Việt Nam [Blue Lotus Sustainable Tourism Label set applicable to tourist accommodation in Vietnam]. Retrieved September 11, 2017, from https://vietnamtourism.gov.vn/dmdocuments/Bo\%20tieu\%20chi\%201355Q\%C3\%90-BVHTTDL.pdf

Brida, J. G., Giacomo, D. C., Marta, M., \& Manuela, P. (2012). The perceptions of an island community towards cruise tourism: A factor analysis. Original Scientific, 60(1), 29-42.

Brida, J. G., Osti, L., \& Faccioli, M. (2011). Residents' perception and attitudes towards tourism impacts: A case study of the small rural community of Folgaria (Trentino-Italy). Benchmarking: An International Journal, 18(3), 359-385.

Chính phủ. (2009). Đề án nâng cao nhận thức cộng đồng và quản lý rủi ro thiên tai dụa vào cộng đồng [Community awareness raising and community-based disaster risk management project]. Retrieved September 12, 2017 from http://vanban.chinhphu.vn/portal/page/portal/chinhphu/hethongvanban?class_id=1\&mo de=detail\&document_id=88942

Chính phủ. (2011). Chiến lược quốc gia về biến đổi khi hậu [National strategy on climate change]. Retrieved September 13, 2017 from https://thuvienphapluat.vn/van-ban/tainguyen-moi-truong/quyet-dinh-2139-qd-ttg-phe-duyet-chien-luoc-quoc-gia-bien-doi- 
khi-hau-132631.aspx Hoàng Trọng và Chu Nguyễn Mộng Ngọc (2008). Phân tích dĩ liệu nghiên cúu với SPSS, NXB Hồng Đức, HàNội.

Dimitrios, S., Avital, B., Jason, S., \& Edith, M. S. (2014). Residents' support for tourism development: The role of residents' place imageand perceived tourism impacts. Tourism Management, 45, 260-274.

Do, T. T., Bui, T. V., \& Nguyen, N. Q. (2016). Các nhân tố ảnh hương đến sụ tham gia vào hoạt động du lịch vuờn sinh thái của hộ gia đình tại huyện Phong Điền, thành phố Cần Tho [Factors affecting a household's participation in ecotourism in Phong Dien district, Can Tho city]. Retrieved September 15, 2017, from https://sj.ctu.edu.vn/q1/docgia/download/baibao-34006/02-KTDO\%20THIEN\%20TOAN(12-19)565.pdf

Gerbing, D. W., \& Anderson, J. C. (1987). Improper solutions in the analysis of covariance structures: Their interpretability and a comparison of alternate respecifications. Psychometrika, 52(1), 99-111.

Hair, J. F., Black, W. C., Babin, B. J., Anderson, R. E., \& Tatham, R. L. (2006). Multivariate data analysis. Upper Saddle River, NJ: Pearson Prentice Hall.

Hair, J., Anderson, R., Tatham, R. L., \& Black, W. C. (1998). Multivariate data analysis (5th ed.). Upper Saddle River, NJ: Prentice-Hall.

Honey, H. (1999). Ecotourism and sustainable development: Who owns paradise? Washington, DC: Island Press.

Huamin, L., \& Xuejing, Z. (2011). Factors on tourist community participation in Dongqian Lake. Proceedings of 2011 2nd International Conference on Artificial Intelligence, Management Science and Electronic Commerce (AIMSEC), Dengleng, 2011, 354-357, doi:10.1109/AIMSEC.2011.6010181.

IPCC. (2007). Climate change 2007: Impacts, adaptation and vulnerability. Contribution of Working Group II to the Fourth Assessment Report of the intergovernmental panel on climate change. Cambridge, UK: Cambridge University Press.

IPCC. (2014). Approved summary for policymakers. In R. K. Pachauri \& L. A. Meyer (Eds.), Climate change 2014: Synthesis report. Contribution of Working Groups I, II and III to the Fifth Assessment Report of the intergovernmental panel on climate change. Geneva, Switzerland: IPCC.

Lo, M.-C., Songan, P., Mohamad, A. A., \& Yeo, A. W. (2013). Rural tourism and destination image: Community perception in tourism planning. The Macrotheme Review, 2(1), 102118

Luu, H. T. D. (2007), Giáo trình quản trị tiếp thị [Curriculum of marketing management]. Ho Chi Minh, Vietnam: NXB Giáo dục.

Nunnally, J. (1978). Psychometric theory (2nd ed.). New York, NY: McGraw-Hill.

Nunnally, J., \& Bernstein, I. (1997). Psychometric theory (3rd ed.). New York, NY: McGrawHill. 
Peterson, R. A. (1994). A meta-analysis of Cronbach's Coefficient Alpha. Journal of Consumer Research, 21(2), 381-391.

Rojana, T. (2013). Community participation and social capital in tourism planning and management in a Thai context. (Doctoral dissertation). Lincoln University, Lincoln, New Zealand.

Rukavina, B., Soemarno, Luchman, H., \& Iwan, N. (2013). Social capital in the development of ecotourism: A case study in Tambaksari Village Pasuruan Regency, East Java Province. $\quad$ Retrieved September 13, 2017, from https://www.researchgate.net/publication/293476076_Social_Capital_in_the_Developm ent_of_Ecotourism_A_Case_Study_in_Tambaksari_Village_Pasuruan_Regency_East_J ava_Province_Indonesia

Slater, S. (1995). Issues in conducting marketing strategy research. Journal of Strategic Marketing, 3(4), 257-270.

Sở Văn hóa, Thể thao và Du lịch. (2016). Kết quả hoạt độngVăn hóa, Thể thao và Du lich năm 2014 phuoong hương, nhiệm vu công tác năm 2016 [Results of Culture, Sports and Tourism activities in 2014, orientation and tasks in 2016] (Report No. 22/BC). Hanoi, Vietnam: Sở Văn hóa, Thể thao và Du lịch.

Subchat, U. (2013). Modeling residents' perceptions on ecotourism in upper mortheast, Thailand. Proceedings of the International Conference on Tourism, Transport, and Logistics, 581-596.

Sun, H. C. (2013). The impacts of tourism and local residents support on tourism development: A case study of the rural community of Jeongseon, Gangwon Province, South Korea. AUGSB e-Journal, 6(1), 73-82.

Tang, C., Zhong, L., \& Cheng, S. (2012). Tibetan attitudes towards community participation and ecotourism. Journal of Resources and Ecology, 3(1), 8-15.

Tatoglu, E., Erdal, F., Ozgur, H., \& Azakli, S. (2002). Resident perceptions of the impact of tourism in a Turkish resort town. Proceeding of the First International Joint Symposium on Business Administration, 745-755.

Tosun, C. (2000). Limits to community participation in the tourism development process in developing countries. Tourism Management, 21(2000), 613-633.

Tsung, H. L. (2012). Influence analysis of community resident support for sustainable tourism development. Tourism Management, 34, 1-10.

Ủy ban nhân dân tỉnh Cà Mau. (2012). Phê duyệt quy hoạch tổng thể phát triển du lịch tỉnh Cà Mau đến năm 2020 và định hương đến năm 2030 [Approving the master plan on tourism development in Ca Mau province to 2020 and orientation to 2030]. Retrieved September 14 , 2017 , from https://www.camau.gov.vn/wps/portal/?1dmy\&page=trangchitiet\&urile=wcm\%3Apath $\% 3 \mathrm{~A} /$ camaulibrary/camauofsite/tiemnangvacohoi/chienluocdinhhuong/quyhoachtntn/ss $\mathrm{XXV}$ 
Yooshik, Y., Dogan, G., \& Joseph, S. C. (2001). Validating a tourism development theory with structural equation modeling. Tourism Management, 22, 363-372

Zhang, Y. (2009). Perceived impacts of tourism oriented urban historic district revitalization: Case study of Yangzhou, China. Retrieved September 15, 2017, from https://www.semanticscholar.org/paper/Perceived-impacts-of-tourism-oriented-urbanCase-of-Zhang/ab5c31bece59ec877b404dda427a3c3c83705d1a 